Steps towards constructing a global comparative risk analysis for alcohol consumption: determining indicators and empirical weights for patterns of drinking, deciding about theoretical minimum, and dealing with different consequences

Rehm, Jürgen ; Monteiro, M ; Room, R ; Gmel, Gerhard ; Jernigan, D ; Frick, Ulrich ; Graham, K

DOI: https://doi.org/10.1159/000050731

Posted at the Zurich Open Repository and Archive, University of Zurich

ZORA URL: https://doi.org/10.5167/uzh-94633

Journal Article

Published Version

Originally published at:

Rehm, Jürgen; Monteiro, M; Room, R; Gmel, Gerhard; Jernigan, D; Frick, Ulrich; Graham, K (2001). Steps towards constructing a global comparative risk analysis for alcohol consumption: determining indicators and empirical weights for patterns of drinking, deciding about theoretical minimum, and dealing with different consequences. European Addiction Research, 7(3):138-147.

DOI: https://doi.org/10.1159/000050731 


\title{
Steps towards Constructing a Global Comparative Risk Analysis for Alcohol Consumption: Determining Indicators and Empirical Weights for Patterns of Drinking, Deciding about Theoretical Minimum, and Dealing with Different Consequences
}

\author{
Jürgen Rehm ${ }^{a-c}$ Maristela Monteiro ${ }^{d}$ Robin Room ${ }^{e}$ Gerhard Gmel $^{f}$ \\ David Jernigang Ulrich Frick ${ }^{h}$ Kathryn Graham ${ }^{b}$ \\ ${ }^{a}$ Addiction Research Institute, Zürich, Switzerland; bCentre for Addiction and Mental Health, Toronto, Ont.; \\ 'University of Toronto, Ont., Canada; ${ }^{d}$ World Health Organization, Geneva, Switzerland; ${ }^{e}$ Centre for Social Research \\ on Alcohol and Drugs, Stockholm University, Stockholm, Sweden; fSwiss Institute for the Prevention of Alcohol and \\ Other Drug Problems, Lausanne, Switzerland; g Marin Institute for the Prevention of Alcohol and Other Drug \\ Problems, San Rafael, Calif., USA, and hUniversity of Regensburg, Germany
}

\section{Key Words}

Alcohol $\cdot$ Burden of disease $\cdot$ Beneficial effect $\cdot$ Risk factor - Global · Methodology · Average consumption · Patterns of drinking

\begin{abstract}
In order to conduct a comparative risk analysis for alcohol within the Global Burden of Disease Study (GBD 2000), several questions had to be answered. (1) What are the appropriate dimensions for alcohol consumption and how can they be categorized? The average volume of alcohol and patterns of drinking were selected as dimensions. Both dimensions could be looked upon as continuous but were categorized for practical purposes. The average volume of drinking was categorized into the following categories: abstention; drinking 1 (>0-19.99 g pure alcohol daily for females, $>0-39.99 \mathrm{~g}$ for males); drinking 2 (20-39.99 g for females, 40-59.99 g for males), and drinking 3 ( $\geq 40 \mathrm{~g}$ for females, $\geq 60 \mathrm{~g}$ for males). Pat-
\end{abstract}

\section{KARGER}

Fax +4161306 1234

E-Mail karger@karger.ch

www.karger.com

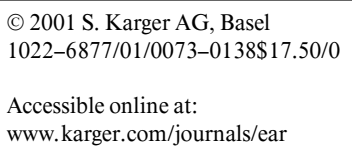

terns of drinking were categorized into four levels of detrimental impact based on an optimal scaling analysis of key informant ratings. (2) What is the theoretical minimum for both dimensions? A pattern of regular light drinking (at most 1 drink every day) was selected as theoretical minimum for established market economies for all people above age 45 . For all other regions and age groups, the theoretical minimum was set to zero. Potential problems and uncertainties with this selection are discussed. (3) What are the health outcomes for alcohol and how do they relate to the dimensions? Overall, more than 60 disease conditions were identified as being related to alcohol consumption. Most chronic conditions seem to be related to volume only (exceptions are coronary heart disease and ischemic stroke), and most acute conditions seem to be related to volume and patterns. In addition, using methodology based on aggregate data, patterns were relevant for attributing harms for men but not women.

Copyright $@ 2001$ S. Karger AG, Basel
Prof. Dr. Jürgen Rehm

Addiction Research Institute

Konradstrasse 32, PO Box

CH-8031 Zürich (Switzerland)

E-Mail jtrehm@isf.unizh.ch or jtrehm@aol.com 
Table 1. Alcohol related morbidity and mortality conditions from major overview studies

\begin{tabular}{|c|c|c|c|}
\hline Disease & ICD-9 & Disease & ICD-9 \\
\hline Lip cancer & 140 & Chronic pancreatitis & 577.1 \\
\hline Tongue cancer & 141 & Spontaneous abortion & 634 \\
\hline Oropharyngeal cancer & $143-146$ & Fetal damage & 655.4 \\
\hline Hypopharyngeal cancer & 148 & Low birth weight & 656.5 \\
\hline Cancer of other sites (lip, mouth, pharynx) & 149 & Psoriasis & 696.1 \\
\hline Esophageal cancer & 150 & Prematurity/intrauterine growth-retardation & 764,765 \\
\hline Liver cancer & 155 & Excess blood alcohol & 790.3 \\
\hline Laryngeal cancer & 161 & Toxic effect of ethyl alcohol & 980.0 \\
\hline Female breast cancer & 174 & Toxic effect of methyl alcohol & 980.1 \\
\hline Oropharyngeal carcinoma & 230.0 & Road injuries & E810-E819 \\
\hline Esophageal carcinoma & 230.1 & Motor vehicle non-traffic accidents & E820-825 \\
\hline Liver carcinoma & 230.8 & Bicycle accidents & E826 \\
\hline Laryngeal carcinoma & 231.0 & Other road vehicle accidents & E829 \\
\hline Breast carcinoma & 233.0 & Water transport accidents & E830-839 \\
\hline Diabetes & 250 & Air-space transport accidents & E840-E845 \\
\hline Alcoholic psychosis & 291 & Alcoholic beverage poisoning & E860.0 \\
\hline Alcohol dependence syndrome & 303 & Other ethanol and methanol poisoning & $\mathrm{E} 860.1, \mathrm{E} 860.2$ \\
\hline Harmful alcohol use & 305.0 & Fall injuries & E880-E888 \\
\hline Epilepsy & 345 & Fire injuries & E890-E899 \\
\hline Alcoholic polyneuropathy & 357.5 & Accidental excessive cold & E901 \\
\hline Hypertension & $401-405$ & Drowning & E910 \\
\hline Coronary heart disease & $410-414$ & Aspiration & E911 \\
\hline Ethylic myocarditis & 425.5 & Striking against/struck by objects & E917 \\
\hline Cardiac arrhythmias & $427.0,427.2,427.3$ & Caught in/between objects & E918 \\
\hline Heart failure and ill-defined descriptions & & Occupational and machine injuries & E919-E920 \\
\hline and complications of heart disease & $428-429$ & Accidental firearm missile & E922 \\
\hline Stroke & $430-438$ & Suicide & E950-E959 \\
\hline Esophageal varices & $456.0-456.2$ & Assault & E960 \\
\hline Gastro-esophageal hemorrhage & 530.7 & Victim assault firearms & E965 \\
\hline Alcoholic gastritis & 535.3 & Visting assault cutting instruments & E966 \\
\hline Alcoholic liver cirrhosis & $571.0-571.3$ & Visting child battering & E967 \\
\hline Unspecified cirrhosis & 577.0 & Visting assault other & E968 \\
\hline Cholelithiasis & 574 & Late effects of injury by another & E969 \\
\hline Acute pancreatitis & 577.0 & & \\
\hline
\end{tabular}

Italics indicate that alcohol consumption may also be beneficial with respect to these disease categories.

\section{Introduction}

The relationship between alcohol and health is complex and multidimensional. At least two dimensions of alcohol consumption have been found to influence disease: overall volume and patterns of drinking. Overall volume was linked to more than 60 disease conditions in a series of recent meta-analyses [1-3] (table 1). The data on patterns of drinking is scarcer, but evidence is accumulating that patterns of drinking affect the link between alcohol and disease [4-7]. In other words, the impact of the average volume of consumption on mortality or morbidity is dependent on how alcohol is consumed in a certain culture. The same amount of alcohol if consumed moderately with meals, for example, may have less detrimental or even beneficial effects compared to consumption as weekend or holiday binges [8]. Therefore, to determine the impact of alcohol on disease burden, both the overall volume and pattern of drinking have to be considered and integrated.

One way of integrating average volume and patterns into the risk relationship that also takes into account the availability of data across most countries is to model the relationship between volume, patterns and mortality with hierarchical models $[9,10]$. In these models, patterns of drinking are seen as moderating the influence of volume on disease. This approach can provide meaningful comparisons across countries because drinking patterns have been found to be relatively stable over time [11, 12].

Using this approach, country-specific weights for the influence of drinking patterns on the relationship between average volume and mortality can be derived (see below 
Table 2. Schema for necessary data to derive attributable fractions

\begin{tabular}{|c|c|c|c|}
\hline Attributable fractions f: & Prevalence & Pattern weight & Relative risk \\
\hline $\begin{array}{l}\text { Defined as: With a given outcome } \\
\text { exposure factor and population, } \\
\text { the attributable fraction is the pro- } \\
\text { portion by which the incidence rate } \\
\text { of the outcome would be reduced if } \\
\text { the distribution of exposure would } \\
\text { change to an alternative distribution }\end{array}$ & $\begin{array}{l}\text { Four drinking categories (abstainer, } \\
\text { drinker } 1,2,3 \text { ) are distinguished. } \\
\text { Prevalence for all four categories } \\
\text { are taken from surveys }\end{array}$ & $\begin{array}{l}\text { Steps to derive at pattern weight: } \\
\text { 1. Determine pattern value from } \\
\text { survey of key informants, and/or } \\
\text { survey data where available } \\
\text { 2. Conduct hierarchical linear } \\
\text { analyses on mortality using per } \\
\text { capita consumption gross-national } \\
\text { product, year (level-1 variables) } \\
\text { and pattern values (level-2 variable) } \\
\text { as determining factors (separate by } \\
\text { age and sex) } \\
\text { 3. Construct pattern weight based } \\
\text { on intercept and regression weight } \\
\text { for patterns }\end{array}$ & $\begin{array}{l}\text { Relative risk estimates } \\
\text { for each drinking cate- } \\
\text { gory are either taken } \\
\text { directly from meta- } \\
\text { analyses (chronic } \\
\text { diseases) or indirectly } \\
\text { from meta-analyses of } \\
\text { attributable fractions } \\
\text { (accidents) }\end{array}$ \\
\hline
\end{tabular}

for details) [for a full derivation of the model including formulas see, 9]. The pattern weights can then be included into the usual epidemiological models to determine the disease burden attributable to alcohol [for the theoretical underpinnings see, $2,13,14]^{1}$ To model the influence of alcohol on disease in these more sophisticated models for different regions of the world, the following information is required (table 2): (1) prevalence of categories of volume of alcohol consumption by sex, age and country; (2) a measure of drinking pattern (pattern value) by country; (3) an estimate of pattern weight modifying the relative risk for disease outcomes where patterns are involved by sex, age and country ${ }^{2}$ (derived from pattern value by hierarchical analysis); (4) a general estimate of relative risk relating average volume categories with disease outcomes, specified for sex and age (from epidemiological literature); (5) mortality data for all disease outcomes related to alcohol by sex, age and country; (6) morbidity and disability data for all disease outcomes related to alcohol by sex, age and country, and (7) counterfactual scenarios for determining the alcohol-attributable fractions of mortality or morbidity.

Table 2 shows how all the different pieces for modeling the burden of disease attributable to alcohol were put into

\footnotetext{
1 Hierarchical models will only be used for determining pattern weights and not for the calculation of burden of disease per se as this calculation is done based on sex, age, and region-specific exposure and outcome data and per capita consumption cannot be used as an indicator for sex- and age-specific drinking.

2 Of course, countries with the same pattern value will have the same pattern weight.
}

place. This paper describes each of these steps in more detail. The actual calculations are reported in Rehm et al. [15].

\section{Prevalence of Categories for Average Volume of Alcohol Consumption}

The following categories for average volume per day of drinking alcohol were selected based on the availability of data for risk analysis evident in major meta-analyses [1-3, 16]. This categorization of average drinking allowed some control of different shapes of risk curves (e.g., linear, Jshape, threshold, etc.), but at the same time allowed studies that only collected categorical information to be used in the meta-analyses ${ }^{3}$ : (1) abstainer (defined as no drinks of alcohol within last year); (2) drinker 1 (females 0$19.99 \mathrm{~g}$ pure alcohol daily, males $0-39.99 \mathrm{~g}$ pure alcohol); (3) drinker 2 (females 20-39.99 g pure alcohol, males 40-59.99 g pure alcohol), and (4) drinker 3 (females $\geq 40$ g pure alcohol, males $\geq 60 \mathrm{~g}$ pure alcohol).

The global burden of disease model requires a disaggregated approach estimating the burden separately by sex, age and countries. Thus, prevalence of these exposure

\footnotetext{
3 We have not used the terminology of English et al. [1] because we believe that this terminology is problematic and potentially stigmatizing. 'Harmful drinkers' clearly are at the highest risk for chronic disease but clearly not every harmful user will experience harm, nor does the word 'harmful' correspond to 'harmful use' as ICD 10 category (F10.1).
} 
Table 3. Patterns of drinking assessed by WHO survey 2000

\begin{tabular}{ll}
\hline Pattern & Link to disease burden \\
\hline Proportion of abstinence & $\begin{array}{l}\text { The same per capita consumption will have more } \\
\text { detrimental effects in countries where drinking is } \\
\text { concentrated among fewer people }\end{array}$ \\
$\begin{array}{l}\text { Heavy drinking occasions } \\
\text { Quantity of alcohol per occasion } \\
\text { Proportion of daily drinking } \\
\text { Getting drunk }\end{array}$ & $\begin{array}{l}\text { The fewer occasions on which a given amount of } \\
\text { alcohol is consumed, the more detrimental the } \\
\text { consequences [33] }\end{array}$ \\
Drinking with meals & $\begin{array}{l}\text { Drinking with meals has been shown in epidemiolo- } \\
\text { gical and biological research to be less detrimental } \\
\text { than drinking at other times [34] }\end{array}$ \\
Drinking in public often requires transportation, and \\
thus has been linked to accidents and injuries [35] \\
Dinking in public places
\end{tabular}

categories can only be derived from surveys because per capita consumption data do not indicate alcohol consumption separately by sex or age.

\section{Measure for Patterns of Drinking by Countries}

In order to provide initial estimates of drinking patterns across a range of countries, a survey of key informants selected by WHO staff was conducted in early 2000. The survey covered relevant drinking characteristics within different countries or regions (see Appendix 1 for a full copy of the questionnaire). Key informants from more than 50 countries responded [17]. In most cases, respondents had some access to national or regional survey data, although these data were not always published in the international literature. In addition, all answers were rated on validity (e.g., whether based on surveys or just best guesses; see appendix 1). The survey considered five main areas of drinking patterns of the culture that might be expected to affect the impact of volume of drinking: proportion of abstinence, heavy drinking occasions, drinking with meals, drinking in public places, and drinking linked to violence (later dropped from analyses because of confounding with outcome measures). The rationale for the impact of each of these drinking patterns is shown in table 3 .

Steps towards CRA for Alcohol
The key informant ratings were analyzed using optimal scaling analysis [18]. Similar to factor analysis, but permitting the simultaneous inclusion of ordinal and categorical data, this statistical technique allows the analyst to determine the number of underlying dimensions and the relation of items to each dimension. In the case of the patterns of drinking analysis, one dimension was identified which we labelled detrimental impact. This dimension had an eigenvalue of 0.29 (maximum 1.0). Eigenvalues are an indication of explained variance of the scaled new variable. Hence, about $29 \%$ of the underlying variance of the scaled variable could be explained.

Table 4 shows the countries in the analysis ordered by their score on the new detrimental impact variable (table 4 , first column). The interpretation of these scores is that the higher the score, the higher the postulated detrimental effects of the same per capita consumption of alcohol on harm. Let us give an example. If two countries have the same level of per capita consumption, and in one country there are $60 \%$ abstainers and in the other country only $10 \%$, we expect more alcohol-related harm in the former country because the same volume of alcohol consumption is spread over fewer drinkers. That is, for a country with a large proportion of consumption to have the same overall per capita consumption of alcohol as a country with few abstainers, those who do consume alcohol in the country with many abstainers must be consuming much more than drinkers in the country with few

Eur Addict Res 2001;7:138-147 
Table 4. Pattern value for detrimental influence of drinking patterns on constant volume

\begin{tabular}{|c|c|c|c|}
\hline Country & $\begin{array}{l}\text { Score on detrimental } \\
\text { drinking pattern from } \\
\text { optimal scaling analysis } \\
\text { of key informant ratings }\end{array}$ & $\begin{array}{l}\text { Score of detrimental } \\
\text { drinking pattern based } \\
\text { on summing the ratings } \\
\text { of key informants }\end{array}$ & $\begin{array}{l}\text { Detrimental } \\
\text { drinking pattern } \\
\text { collapsed into } 4 \\
\text { general categories }\end{array}$ \\
\hline Germany & -1.75 & 1 & 1 \\
\hline UK & -1.54 & 1 & 1 \\
\hline Australia & -1.38 & 1 & 1 \\
\hline New Zealand & -1.26 & 3 & 1 \\
\hline Denmark & -1.17 & 2 & 1 \\
\hline Spain & -1.14 & 3 & 1 \\
\hline Japan & -1.04 & 2 & 1 \\
\hline France & -0.96 & 3 & 1 \\
\hline China (South) & -0.95 & 4 & 2 \\
\hline Italy & -0.94 & 3 & 1 \\
\hline Bulgaria & -0.69 & 5 & 2 \\
\hline China (North) & -0.58 & 6 & 2 \\
\hline Canada & -0.55 & 4 & 2 \\
\hline Nigeria (Christian) & -0.51 & 5 & 2 \\
\hline Greece & -0.51 & 4 & 2 \\
\hline Poland & -0.31 & 5 & 2 \\
\hline Nigeria (Moslem) & -0.24 & 5 & 2 \\
\hline Brazil & -0.21 & 7 & 3 \\
\hline Sweden & -0.15 & 5 & 2 \\
\hline Czech Republic & -0.1 & 6 & 2 \\
\hline Israel & 0.02 & 6 & 2 \\
\hline Finland & 0.11 & 6 & 2 \\
\hline Trinidad \& Tobago & 0.2 & 5 & 2 \\
\hline Norway & 0.52 & 8 & 3 \\
\hline Ukraine & 0.6 & 6 & 2 \\
\hline Slovak Republic & 0.6 & 7 & 3 \\
\hline Peru & 0.62 & 9 & 3 \\
\hline Mexico & 0.67 & 10 & 4 \\
\hline Argentina & 0.76 & 5 & 2 \\
\hline Seychelles & 0.88 & 9 & 3 \\
\hline Ireland & 0.99 & 8 & 3 \\
\hline Papua New Guinea & 1.21 & 8 & 3 \\
\hline South Africa & 1.36 & 8 & 3 \\
\hline Philippines & 1.45 & 8 & 3 \\
\hline Thailand & 1.79 & 9 & 3 \\
\hline India & 1.85 & 12 & 4 \\
\hline Zambia & 2.53 & 13 & 4 \\
\hline
\end{tabular}

The higher the value, the higher the predicted detrimental impact of the same per capita consumption. More explanations can be found in the text. abstainers. Similarly, a cultural pattern of drinking that includes a higher number of heavy drinking occasions, more frequent intoxication, more public drinking, and less drinking with meals should all be linked to more harm for a given level of per capita consumption.

Looking at table 4, we would expect the same level of per capita consumption to be linked to fewer problems in countries like Germany and the UK, and to more prob- lems in Zambia. Please note that this pattern value does not reflect the absolute amount of alcohol-related harm in the countries in any way. Clearly, Germany will have more alcohol-related harm per capita than, for instance, the Philippines, because there is much more alcohol consumed per capita in Germany. However, 1 liter of per capita consumption of pure alcohol in the Philippines is expected to be linked to more harm than 1 liter per capita 
of consumption in Germany because that liter of alcohol is concentrated in a smaller number of people in the Philippines and because it is consumed on heavier drinking occasions, less with meals, etc.

The results of the optimal scaling analysis (table 4, first column) were very similar to a score derived simply by summing the ratings of the key informant survey (table 4, second column; Pearson correlation 0.93). To further simplify the pattern values into robust general categories based on these scale values, the countries were classified into four categories and assigned values from 1 to 4 (table 4, third column).

To apply pattern values to estimating the burden of disease attributable to alcohol, countries with missing data on drinking pattern values were assigned the same category as that of neighboring countries taking into consideration geographic and cultural proximity. The pattern values for more than 100 countries worldwide can be seen in Appendix 2. As part of the process of developing these ratings, the list of derived and assigned pattern values shown in Appendix 2 was made available on a WHO listserve to a large number of key informants for critical assessment. The pattern of drinking thus defined proved to be unrelated to volume: the overall Pearson correlation between pattern values and per capita consumption for the 101 countries is -0.16 and does not even achieve statistical significance; that is, it is not significantly different from zero.

Although this procedure allowed us to derive pattern values from a combination of empirical data and expert judgement, these patterns still needed to be validated empirically to demonstrate that they were, in fact, related to outcomes. In other words, pattern values serve as a description of one aspect of exposure that is theoretically postulated to relate to harm, but such a relation still has to be empirically established. In addition, the degree of influence of patterns on harm (i.e., how much weight to assign to drinking pattern in calculating the burden of disease attributable to alcohol) has to be estimated. Moreover, the weight to assign drinking pattern may vary by outcome, sex and age. Therefore, as described in the following, hierarchical linear analyses with all-cause mortality as the summary outcome were used to determine pattern weights [19].

\section{Determining Drinking Pattern Weight from Pattern Values for Modifying the Relative Risk for Disease Outcomes where Patterns Are Involved}

To determine pattern weights, hierarchical linear analyses were conducted using a pilot sample of 29 European countries $^{4}$ with data for at least 3 consecutive years in the $1990 \mathrm{~s}^{5}$ on each of the following variables: per capita alcohol consumption for the population above 15 years of age, unrecorded consumption, standardized mortality and per capita gross national product (level-1 variables), as well as an estimate of patterns of drinking for that time period (level-2 variable). Calendar year was used to control for omitted variable bias and the time structure [10]; per capita gross national product was included to control for poverty as a potential confounder. The data were taken from the following sources.

(1) Mortality data were obtained from the WHO data bank and age-standardized using UN population estimates. Direct standardization of mortality rates was performed using the latest WHO World Standard Population [20], which is shown in figure 1 . The reference population is quite 'young' with regard to the population distributions in established market economies (fig. 1, 'Scandinavian standard') but better reflects developing and emerging economies. On the other hand, the new WHO standard takes into account the reduced mortality rates in the older age groups nowadays which have shaped a distribution a little 'older' than the formerly widespread used Segi [21] standard (fig. 1).

(2) Per capita alcohol consumption data (for the population 15+) was taken from the global status report on alcohol [22] and the databank of the Marin Institute for the Prevention of Alcohol and Other Drug Problems ${ }^{6}$.

(3) Per capita gross national product data were taken from the World Bank statistics, which used the Atlas method to arrive at standardized, de-inflated values in current (year 2000) US dollars.

For these 29 countries, time series data were collected from 1963 onwards on the four level-1 variables (stan-

\footnotetext{
4 Europe was taken as a pilot as data availability is highest there. The final analysis will include all countries worldwide which fulfill the criteria on available data.

5 Three consecutive years during the 1990s was the inclusion criterion for the respective country for this pilot study, although time series started in 1963 for most countries, sometimes with missing values for single years.

6 The Marin Institute for the Prevention of Alcohol and Other Drug Problems was responsible for producing e and updating the databank underlying the last Global Status Report on Alcohol from 1999. Without this databank we would have been unable to conduct the comparative risk analysis on alcohol.
} 
Fig. 1. Comparison of standard population distributions.

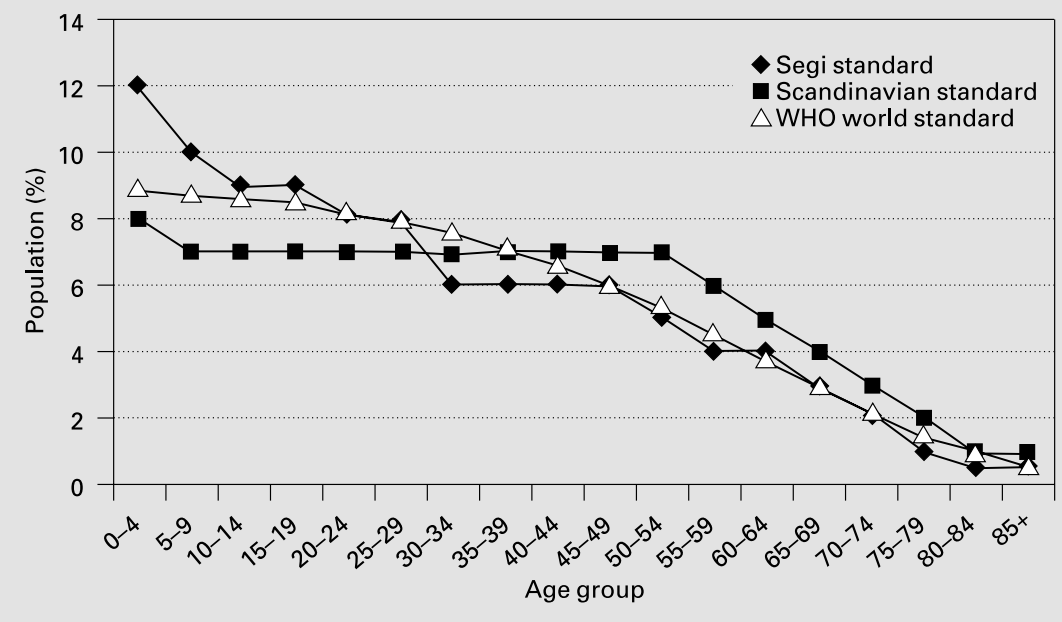

dardized mortality, calendar year, per capita alcohol consumption, per capita gross national product). The country-specific time series varied in length from 3 to 26 years. Random intercept and random coefficient models were analyzed to determine the influence of patterns of drinking on consumption. Greater detail on the equations used can be found in Rehm and Gmel [9]; a detailed comparison of alternative methods and their results is given in Gmel et al. [10]. Separate analyses were conducted for males and females.

Most chronic conditions seem to be related to volume only (exceptions are coronary heart disease and ischemic stroke), and most acute conditions seem to be related to volume and patterns. The effect of patterns of drinking on mortality was significant only for males in most age categories. Therefore, drinking pattern was included as a weighting factor in the respective derivation of attributable fractions (AFs) for males. For females, no significant effect appeared. This may well reflect the fact that measures of per capita consumption and drinking pattern are heavily dominated by male drinking.

Mortality in country X at time $t$ was modeled as a function of the per capita consumption volume at that time in the respective country:

$$
\text { Mortality }_{\mathrm{xt}}=\beta_{0 \mathrm{x}}+\beta_{1 \mathrm{x}} \text { per capita consumption } \mathrm{xt}+\ldots+\varepsilon_{\mathrm{xt}} \text {. }
$$

The impact of 1 unit of per capita consumption on mortality thus is constant in time, but specific per country and denoted by $\beta_{1 \mathrm{x}}$. This impact itself (throughout this paper called 'pattern weight' is regarded as both a dependent variable and predictor variable for which the value not only varies across countries, but also systematically depends on drinking pattern (labeled 'pattern value' observed in the respective country.

Pattern weight $=\beta_{1 \mathrm{x}}=\gamma_{10}+\gamma_{11}$ pattern value $\mathrm{x}_{\mathrm{x}}+\mathrm{u}_{1 \mathrm{x}}$.

The coefficient $\gamma_{10}$ can be regarded as a global measure for the impact of per capita consumption on mortality separated from the country-specific modifications. Note that this measure would not be the same if we estimated in a simple one level analysis a global coefficient $\gamma_{1}$ (not varying across countries). The coefficient $\gamma_{11}$ can be regarded as the contribution of the drinking patterns to modify the detrimental effects of per capita consumption on mortality. This modifying effect is the same for all countries. But clearly drinking patterns vary across countries and therefore the impact on mortality $\beta_{1 \mathrm{x}}$ is specific per country. Unexplained variation may remain in these country-specific impact coefficients. This is expressed by the level- 2 error term $u_{1 x}$. It is not assumed that the level- 1 error term $\varepsilon_{\mathrm{xt}}$ and a level-2 error term like $\mathrm{u}_{1 \mathrm{x}}$ are uncorrelated.

The following is an example of how the effects of drinking patterns translated into relative pattern weights for different age groups: if one takes France or Italy as 1, then Norway or Finland as countries with an overall pattern weight of 4 would have a 4.2 -fold higher risk of mortality for each liter of pure alcohol consumed per capita in the age group of 15- to 29-year-olds, and a 1.5-fold higher risk of mortality for the whole population. In other words, the influence of patterns seemed to vary not only by sex but also by age. 


\section{Computing Relative Risks by Sex and Age by Relating Average Volume Categories with Disease Outcomes}

Relative risk estimates for the relationship between categories of volume of drinking (e.g., abstainers, moderate, hazardous, harmful) were taken from the latest metaanalyses [3]. These estimates are sex- and age-specific for causes of disease where the underlying epidemiological data allowed such a differentiation [1,13]. This approach assumes that the relationship between volume of drinking and mortality/morbidity is specific for each disease but does not vary across countries. The prevalence of drinking category and relative risk estimates can then be combined to yield disease-specific AFs using standard epidemiological formulas [1, 13; CRA guidelines http://www.ctru. auckland.ac.nz/CRA/main.html].

For acute conditions, data on drinking patterns were used in the following way. The average AF for each condition was calculated based on a review of the literature using direct methods (e.g., not deriving AFs from prevalence and relative risk, but directly from social statistics, for instance accident statistics specifying the proportion of alcoholrelated accidents based on police records). The average AF was converted into a relative risk estimate assuming loglinear increasing risk over the drinking categories. For the derivation of the revised country-specific AFs, the relative risks, the pattern weights and the prevalence figures were then combined. Pattern weights were assumed to be similar across volume categories (e.g., moderate, hazardous, harmful), which is the assumption used in the derivation of the pattern weights (see above), and which can be justified from empirical data from an individual-level epidemiological study on all-cause mortality [23].

\section{Mortality Data for All Disease Outcomes Related to Alcohol by Sex, Age and Region}

These data were taken from the WHO EIP mortality data bank.

\section{Morbidity and Disability Data for All Disease Outcomes Related to Alcohol by Sex, Age and Region}

WHO EIP will eventually make these data available. Morbidity and disability data will include incidence, prevalence, duration, case fatality and disability weight [24].

Steps towards CRA for Alcohol

\section{Counterfactual Scenarios for Determining the Alcohol-Attributable Fractions of Mortality or Morbidity}

Counterfactual scenarios are necessary to derive attributable and avoidable risk associated with a certain exposure. Traditionally, the counterfactual scenario used was no exposure at all (e.g., what would happen if there was no alcohol at all?), but later developments of epidemiological methodology called for more sophisticated scenarios, e.g., using a theoretical minimum or feasible or plausible distributions of exposure in a population as counterfactual scenarios [14]. In addition to modeling the attributable burden as the deviation of actual drinking from the theoretical minimum [14; CRA guidelines http://www.ctru. auckland.ac.nz/CRA/main.html], cultural limits (e.g., abstinence requirements based on religious reasons) and real population distributions should be integrated in different scenarios and sensitivity analyses.

Compared to usual comparative risk analysis as prescribed by the WHO [http://www.ctru.auckland.ac.nz/ CRA/main.html], alcohol poses specific problems as a risk factor because alcohol has been shown to have a preventive effect for some diseases $[3,25,26]$. The theoretical minimum ${ }^{7}$ thus does not seem to be fixed and seems to depend on the mix of diseases in a certain region. In the analyses of English et al. [1], the 'moderate drinker' category was defined as optimal (i.e., used as the counterfactual scenario). In a broader global perspective, however, this category would be considered the 'theoretical minimum' risk only in limited circumstances. In particular, the theoretical minimum for older age groups in countries that have low risk drinking patterns may be one drink a day $[1,27]$. However, it should be stressed that this is a theoretical minimum because in reality such drinking patterns are quite rare [28]. In general, the theoretical minimum would be zero for populations with no or very few risk for ischemic diseases (e.g., low proportion of these diseases in age groups under $45[27,29,30])$. The theoretical minimum should also be zero in populations with very detrimental drinking patterns (e.g., there is no benefit for ischemic diseases if alcohol is consumed as one bottle of wine every Friday which would yield an average of 1 drink per day, but in a detrimental pattern [7].

The theoretical minimum risk distribution is defined as 'the distribution of exposure that would have the lowest associated population risk, or in other words, would generate the largest estimate of attributable and avoidable burden' [14, p 597].

Eur Addict Res 2001;7:138-147 
An additional consideration in determining theoretical minima for alcohol is the preponderance in available studies of mortality as an outcome. It has been argued that morbidity and disability, as well as social outcomes, may have a different minimum. However, at this time, there are insufficient data to determine different theoretical minima for alcohol for mortality and morbidity.

In sum, a pattern of regular light drinking (at most one drink every day) was selected as theoretical minimum for established market economies for all people above age 45 . For all other regions and age groups, the theoretical minimum was set to zero. However, because no single theoretical minimum can be justified for alcohol as a risk factor, we strongly argue that the concept of a theoretical minimum should be abandoned. Instead, we propose that a number of sensitivity analyses using different assumptions be conducted.

\section{Conclusions}

From a substantive point of view, patterns of drinking were found to influence the overall mortality attributable to alcohol to a considerable degree, especially in young people in Europe [10]. This is not surprising, as young people often die from acute causes of death, especially accidents. However, most analyses appearing in the literature are still restricted to average volume of drinking [for example, on the aggregate level, see the contributions in Addiction supplement 1, 2001, and for the individual level see, 2, 27]. Clearly, the failure to include pattern indicators is linked to the slow change of introducing pattern variables into standard medical epidemiology [31, 32].

Even if empirical measures of patterns were introduced immediately into medical epidemiology, there would still be some time before pattern weights could be derived from individual level epidemiological studies in the same way we derive relative risk estimates, as years typically elapse before outcomes are measured in such studies. In the interim, in order to model consequences of alcohol we need some estimates both for pattern values and pattern weights.

The methods introduced here, i.e. getting a pattern value from key informant surveys and determining pattern weights in hierarchical linear analysis, proved feasible. Of course, the end result can only be as good as the input. In this light, the data on pattern values from the expert survey can be considered the weakest link in the procedure. To improve the quality of these data, it would certainly be worthwhile to organize a new key informant survey with more specific questions and stressing the need for searching for empirical data, even if they are only partially applicable.

There remains the problem that the method applied here did not produce pattern weights for females, which were significantly different from zero. This may reflect reality (e.g., females may consume alcohol in a less detrimental way) or it may be just due to fact that per capita consumption measures used to derive pattern weights did not constitute a good indicator for female drinking (see above). We suspect the latter explanation is the main reason for this finding. However, the impact of patterns for females also did not show statistical significance in some individual level studies [23]. Female drinking patterns and their impact is a topic which has to be analyzed further in the future.

In summary, even though they can be improved, the overall methods are feasible and seem promising. In a global perspective, it is no longer justifiable to base estimates of health consequences of drinking solely on volume of drinking, without taking account of the drinking pattern.

\section{Acknowledgements}

Parts of this article were made available on the World Health Organization (WHO) listserve for discussion. We would like to thank all who responded there. The authors would also like to thank the participants in the WHO experts' meeting on alcohol as a risk factor for the burden of disease in Geneva, Switzerland, January 29-30, 2001, for valuable comments in revising prior versions: Jennifer Hildebrand, Maria-Elena Medina-Mora, Zofia Mielecka-Kubien, Ian B. Puddey, Margret Rihs-Middel, Jussi Simpura. The WHO, the Swiss Federal Office of Public Health (contract No. 00.001588), the Addiction Research Institute in Zurich, Switzerland, the Swiss Institute for the Prevention of Alcohol and Other Drug Problems, Lausanne, and the Centre for Addiction and Mental Health in Toronto, Ont., Canada provided financial support for this study. 


\section{References}

1 English DR, Holman CDJ, Milne E, Winter MJ, Hulse GK, Codde G, Bower CI, Cortu B, de Klerk N, Lewin GF, Knuiman M, Kurinczuk JJ, Ryan, GA: The Quantification of Drug Caused Morbidity and Mortality in Australia 1995. Canberra, Commonwealth Department of Human Services and Health, 1995.

2 Single E, Robson L, Rehm J, Xie X: Morbidity and mortality attributable to alcohol, tobacco, and illicit drug use in Canada. Am J Public Health 1999;89:385-390.

3 Gutjahr E, Gmel G, Rehm J: The relation between average alcohol consumption and disease: An overview. Eur Addict Res 2001;7: 117-127.

4 Rehm J, Ashley MJ, Room R, Single E, Bondy SJ, Ferrence R, et al: Drinking patterns and their consequences: Report from an international meeting. Addiction 1996;91:16151621 .

5 Mc Elduff P, Dobson AJ: How much alcohol and how often? Population-based case-control study of alcohol consumption and risk of major coronary event. Br Med J 1997;314: 1159-1164.

6 Bondy SJ: Drinking patterns and their consequences: Report from an international meeting - Overview of studies on drinking patterns and consequences. Addiction 1996;91:1663-1674.

7 Puddey IB, Rakic V, Dimmitt SB, Beilin LJ: Influence of pattern of drinking on cardiovascular disease and cardiovascular risk factors A review. Addiction 1999;94:649-663.

8 Room R, Carlini Cotrim B, Gureje O, Jernigan D, Mäkelä K, Marshall M, Medina-Mora ME, Monteiro M, Parry C, Partanen J, Riley L, Saxena S: Alcohol in a Changing World: Drinking Patterns and Problems in Developing Societies. Cambridge, Cambridge University Press, in press.

9 Rehm J, Gmel G: Gaps and needs in international alcohol epidemiology. J Subst Use 2000; 5:6-13.

10 Gmel G, Rehm J, Frick U: Methodologica approaches to conducting pooled cross-sectional time series analysis: the example of the EU states. Eur Addict Res 2001;7:128-137.

11 Simpura J: Trends in alcohol consumption and drinking patterns: Sociological and economic explanations and alcohol policies. Nord Stud Alcohol Drugs 2001;18(English suppl):3-13.
12 Room R: The impossible dream? Routes to reducing alcohol problems in a temperance culture. J Subst Abuse 1992;4:91-106.

13 Single E, Robson L, Xie X, Rehm J, in collaboration with Moore $\mathrm{R}$, et al: The Costs of Substance Abuse in Canada. Ottawa, Canadian Centre on Substance Abuse, 1996.

14 Murray CJL, Lopez A: On the comparable quantification of health risks: Lessons from the Global Burden of Disease Study. Epidemiology 1999,10:594-605.

15 Rehm J, Gmel G, Room R, Frick U: Average volume of alcohol consumption, drinking patterns and related burden of mortality in young people in established market economies of Europe. Eur Addict Res 2001;7:148-151.

16 Holman CDAJ, English DR, Milne E, Winter MG: Meta-analysis of alcohol and all-cause mortality: A validation of NHMRC recommendations. Med J Aust 1996;164:141-145.

17 Trotter RT, Rehm J, Chatterji S, Room R, Üstün TB: Cross-Cultural Applicability Research (CAR) Methods; in Üstün TB, Chatterji S, Bickenbaach JE, Trotter RT, Room R, Rehm J, Saxena S (eds): Disability and Culture: Universalism and Diversity. Göttingen, Hogrefe \& Huber, 2001

18 Bijleveld CCJH, van der Kamp LJT: Longitudinal Data Analysis: Designs, Models and Methods. London, Sage Press, 1998, pp 46154.

19 US Department of Health and Human Services: 10th Special Report to the US Congress on Alcohol and Health: Highlights from Current Research. Rockville, US Department of Health and Human Services, Public Health Service, National Institutes of Health, National Institute on Alcohol Abuse and Alcoholism, 2000, vol 97, p 4017.

20 Ahmad OB, Boschi-Pinto C, Lopez AD, Murray CJL, Lozano $\mathrm{R}$, Inoue M: Age Standardization of Rates: A New WHO World Standard. GPE Discussion Paper Ser No. 31. Geneva, EIP/GPE/EBD World Health Organization, 2000.

21 Segi, M. Cancer mortality for selected sites in 24 countries (1950-57). Sendai, Department of Public Health, Tohoku University of Medicine, 1960.

22 World Health Organization: Global Status Report on Alcohol. Geneva, World Health Organization Substance Abuse Department, 1999.
23 Rehm J, Greenfield TK, Rogers JD: Average volume of alcohol consumption, patterns of drinking and all-cause mortality. Results from the US National Alcohol Survey. Am J Epidemiol 2001;153:64-71

24 Murray CJL, Lopez A: The Global Burden of Disease: A Comprehensive Assessment of Mortality and Disability from Diseases, Injuries and Risk Factors in 1990 and Projected to 2020. Boston, Harvard School of Public Health on behalf of the World Health Organization and the World Bank, 1996.

25 Chadwick DJ, Goode JA: Alcohol and Cardiovascular Diseases. Chichester, Wiley, 1999.

26 Ashley MJ, Rehm J, Bondy S, Single E, Rankin $\mathrm{J}$ : Beyond ischemic heart disease: Are there other health benefits from drinking alcohol? Contemporary Drug Problems, in press.

27 Rehm J, Gutjahr E, Gmel G: Alcohol and allcause mortality: A pooled analysis. Contemporary Drug Problems, in press.

28 Knupfer G: Drinking for health: The daily ligh drinker fiction. Br J Addict 1987:82:547-555.

29 Rehm J, Sempos CT: Alcohol consumption and mortality - Questions about causality, confounding and methodology. Addiction 1995; 90:493-498.

30 Rehm J, Sempos CT: Alcohol consumption and all-cause mortality Addiction 1995;90: 471-480.

31 Feunekes GIJ, van't Veer P, van Staveren WA, Kok F: Alcohol intake assessment: The sober facts. Am J Epidemiol 1999; 150:105-112.

32 Rehm J: Re: 'Alcohol intake assessment: The sober facts'. Am J Epidemiol 2000;151:436438.

33 Walsh G, Rehm J: Daily drinking and harm. Contemporary Drug Problems 1996;23:465478.

34 Veenstra J, Ockhuizen T, van de Pol, Wedel M, Schaafsma G: Effects of moderate dose of alcohol on blood lipids and lipoproteins postprandially and in the fasting state. Alcohol 1990;25: 371-377.

35 Fahrenkrug H, Rehm J: Trinkkontexte und Freizeitaktivitäten in der Vorphase alkoholbezogener Strassenverkehrsunfälle junger Fahrerinnen und Fahrer in der Schweiz. Sucht 1994; 41:169-180. 